\title{
OS CONSELHOS DE DEFESA DE DIREITOS DAS CRIANÇAS E ADOLESCENTES E O DIREITO À EDUCAÇÃO
}

\author{
LOS CONSEJOS PARA LA DEFENSA DE LOS DERECHOS DE NIÑOS Y \\ ADOLESCENTES Y EL DERECHO A LA EDUCACIÓN
}

\author{
THE COUNCILS FOR THE DEFENSE OF THE RIGHTS OF CHILDREN AND \\ ADOLESCENTS AND THE RIGHT TO EDUCATION
}

\author{
Ana Maria FALSARELLA ${ }^{1}$
}

RESUMO: O artigo, decorrente de levantamento legal, jurídico e bibliográfico, aponta alterações na relação da sociedade brasileira com as novas gerações, que ocorrem a partir de finais dos anos 1980, quando crianças e adolescentes se tornam legalmente cidadãos de direitos. Trata da mudança de perspectiva que ocorreu nas políticas de atenção à infância e à adolescência com a promulgação da Constituição Federal de 1988, do Estatuto da Criança e do Adolescente (ECA, Lei n. 8.069/1990) e da Lei de Diretrizes e Bases da Educação (LDB, Lei n. 9394/1996). Analisa os paradigmas fundantes do ECA e a atuação dos conselhos voltados à garantia dos direitos: o Conselho dos Direitos da Criança e do Adolescente e o Conselho Tutelar. Indica as prerrogativas do Ministério Público e da Justiça da Infância e da Juventude. Enfatiza o papel da escola na garantia dos direitos das crianças e adolescentes, em especial o direito à educação escolar.

PALAVRAS-CHAVE: Políticas de atenção à infância e à adolescência. Conselhos de direitos da criança e do adolescente. Conselho tutelar. Direito à educação escolar. Papel da escola.

RESUMEN: El artículo, resultante de una encuesta legal, jurídica y bibliográfica, señala cambios en la relación de la sociedad brasileña con las nuevas generaciones, que ocurrió a fines de la década de 1980, cuando los niños y adolescentes quedaron legalmente sujetos a derechos. Se trata del cambio de perspectiva que ocurrió en las políticas de atención a niños y adolescentes con la promulgación de la Constitución Federal de 1988, el Estatuto de Niños y Adolescentes (ECA, Ley n. 8.069 / 1990) y la Ley de Directrices y Bases de Educación (LDB, Ley $N^{\circ}$ 9394/1996). Analiza los paradigmas fundacionales de ECA y el desempeño de los consejos destinados a garantizar los derechos: el Consejo para los Derechos de Niños, Niñas y Adolescentes y el Consejo de Tutela. Indica las prerrogativas del Ministerio Público y la Justicia Infantil y Juvenil. Destaca el papel de la escuela para garantizar los derechos de los niños y adolescentes, especialmente el derecho a la educación escolar.

PALABRAS CLAVE: Políticas de atención a niños y adolescentes. Consejos para los derechos de niños y adolescentes. Consejo tutelar. Derecho a la educación escolar. Rol escolar.

${ }^{1}$ Universidade de Araraquara (UNIARA), Araraquara - SP - Brasil. Docente no Programa de Pós-Graduação em Processos de Ensino, Gestão e Inovação. Doutorado em Educação (PUC-SP). ORCID: https://orcid.org/00000002- 0021-2471.E-mail: am.nallin48@gmail.com 
ABSTRACT: The article, resulting from a legal, juridical and bibliographic survey, points out changes in the relationship of Brazilian society with the new generations, which occurred from the end of the 1980s, when children and adolescents became legally subject to rights. It deals with the change of perspective that occurred in the policies of attention to children and adolescents with the promulgation of the Federal Constitution of 1988, the Statute of Children and Adolescents (ECA - Portuguese initials -, Law no. 8,069/1990) and the Law of Guidelines and Bases of Education (LDB - Portuguese initials -, Law no. 9394/1996). It analyzes the founding paradigms of ECA and the performance of councils aimed at guaranteeing rights: the Council for the Rights of Children and Adolescents and the Guardianship Council. Indicates the prerogatives of the Public Ministry and the Child and Youth Justice. Emphasizes the role of the school in guaranteeing the rights of children and adolescents, especially the right to school education.

KEYWORDS: Child and adolescent care policies. Councils for the rights of children and adolescents. Guardianship council. Right to school education. School role.

\section{Introdução}

Esse artigo sinaliza mudanças que ocorreram na relação da sociedade brasileira com as novas gerações, desde os finais dos anos de 1980, quando as crianças e os adolescentes deixam de ser vistos apenas como tutelados e passam a ser qualificados como sujeitos de direitos.

A política de atenção à infância e à adolescência no Brasil sofreu profundas alterações com a promulgação da Constituição Federal de 1988, do Estatuto da Criança e do Adolescente (BRASIL, ECA, Lei n. 8.069/1990) e da Lei de Diretrizes e Bases da Educação (BRASIL, LDB, Lei n. 9394/1996). Também teve sua influência a Lei Orgânica da Assistência Social (BRASIL, LOAS, Lei ${ }^{\circ} 8.742 / 1993$ ). No presente texto abordo os paradigmas constantes no ECA e atuação dos conselhos nele previstos, voltados à garantia dos direitos das crianças e adolescentes no âmbito dos municípios, onde a educação se efetiva: o Conselho Municipal dos Direitos da Criança e do Adolescente e o Conselho Tutelar.

Com o texto, busco fazer uma compilação do que existe no Brasil sobre a defesa dos direitos das crianças e adolescentes. Embora traçando uma visão geral do contexto em que as mudanças ocorrem, enfatizo a educação. Trato mais da fundamentação legal, política e filosófica da questão do que da efetivação propriamente das garantias. A respeito disso, inúmeras pesquisas existem e podem ser encontradas em portais oficiais e acadêmicos e sites referentes ao tema. ${ }^{2}$

2 Tomo a liberdade de indicar duas dissertações de mestrado: “Adolescente em Liberdade Assistida: análise quanto às dificuldades de (re)inserção na rede regular de ensino público em um município do interior paulista" (BANDEIRA, 2016) e "Gestão pedagógica na educação infantil: a relação da escola com as famílias de alunos ingressantes” (ESTEVES, 2019). 
Lembro aos leitores que a legislação, por si, não muda a realidade, mas indica caminhos e orienta o cidadão e a sociedade sobre seus direitos e garantias, possibilitando a cobrança do cumprimento do que nela está contido.

A partir da promulgação da Constituição Federal (BRASIL, 1988) intensificou-se o processo de discussão das políticas sociais voltadas ao enfrentamento da pobreza. Movimentos sociais organizados e alguns setores do poder público lutaram pelo estabelecimento de uma nova ordem jurídico-institucional para o trato dessa questão. Com relação à infância e adolescência, a Carta Magna, no art. 227, afirma que:

É dever da família, da sociedade e do Estado assegurar à criança e ao adolescente, com prioridade absoluta, o direito à vida, à saúde, à alimentação, à educação, ao lazer, à profissionalização, à cultura, à dignidade, ao respeito, à liberdade e à convivência familiar e comunitária, além de colocá-los a salvo de toda forma de negligência, discriminação, exploração, violência, crueldade e opressão (BRASIL, 1988).

Em simetria vertical, a legislação infraconstitucional vem no mesmo sentido de garantir a educação como direito público subjetivo $^{3}$, tanto por meio do ECA, do qual tratarei mais detalhadamente adiante, quanto por meio da LDB, que reza no art. $2^{\circ}$ : “A educação, dever da família e do Estado, inspirada nos princípios de liberdade e nos ideais de solidariedade humana, tem por finalidade o pleno desenvolvimento do educando, seu preparo para o exercício da cidadania e sua qualificação para o trabalho".

Paralelamente ao ECA existe outra lei infraconstitucional, a Lei Orgânica da Assistência Social (LOAS - Lei $n^{\circ}$ 8.742/1993), cuja destinação é o subconjunto da população que se encontra em estado de necessidade, atendendo aos arts. 203 e 204 da CF/1988, os quais incluem, obviamente, crianças e adolescentes. Acontece que, muitas vezes, os órgãos executores da política de atendimento aos direitos da criança e do adolescente, principalmente no que diz respeito às medidas protetivas, se confundem com os órgãos responsáveis pela execução dos programas de assistência social, criando uma zona nebulosa quanto às responsabilidades, uma vez que muitas entidades de atendimento aos direitos da criança e do adolescente têm natureza assistencial. Daí a relevância do mapeamento dos recursos disponíveis em dada região e da integração entre os órgãos, pautada em normas e critérios claros.

\section{O estatuto da criança e do adolescente}

${ }^{3}$ Direito público subjetivo quer dizer que o não oferecimento ou a oferta irregular do ensino obrigatório pelo poder público em qualquer de suas instâncias implica em responsabilização jurídica da autoridade competente. 
O ECA, que regulamenta o art. 227 da $\mathrm{CF}$, não é uma lei voltada a um segmento específico da infância e da juventude, mas abrange o conjunto das crianças e dos adolescentes do Brasil. Esta lei representa a incorporação, na legislação brasileira, dos paradigmas da Convenção Internacional dos Direitos da Criança, aprovada pela Assembleia das Nações Unidas em 20 de novembro de 1989. A doutrina que preside a elaboração do Estatuto é a Doutrina da Proteção Integral, das Nações Unidas, que pode ser resumida na seguinte expressão: "Todos os direitos para todas as crianças" (GOMES DA COSTA, 2016). A doutrina de proteção integral preconizada pelo ECA é uma decorrência natural das regras estabelecidas por normas internacionais e pela $\mathrm{CF}$ e reforça a garantia dos direitos nela previstos, norteando toda a política de atendimento aos cidadãos que se encontram na faixa etária anterior aos 18 anos.

De acordo com a Agência de Notícias dos Direitos da Infância (ANDI), é importante que seja adotada uma terminologia alinhada com os paradigmas preconizados pelas normas de direito internacional e nacional. Nesse sentido, o termo menor, antes utilizado para definir a pessoa com menos de 18 anos, caiu em desuso, pois é considerado como tendo um sentido subjetivo, vago, inapropriado e pejorativo. Desde que o ECA entrou em vigor, passou-se a entender que o termo menor reproduz e endossa discriminações arraigadas e uma postura de exclusão social. Vejamos porquê. A ideia de maioridade diz respeito à idade em que uma pessoa passa a ser considerada capaz de usufruir seus direitos, exercer obrigações e ser responsabilizada civil e criminalmente por seus atos. Menoridade significaria, então, que a criança e o adolescente ainda não gozariam de seus direitos como cidadãos. Ao abolir esse conceito, abriu-se uma nova perspectiva para o atendimento às vítimas de violação de direitos fundamentais, deixando-se de atribuir às famílias pobres a culpa pela situação de exclusão e vulnerabilidade de seus filhos. O novo paradigma define ainda que deve ser assegurada prioridade absoluta ao atendimento às necessidades e direitos das crianças (de zero até 12 anos) e dos adolescentes (de 13 a 18 anos), haja vista sua condição de pessoas em processo de desenvolvimento.

Assim, entende-se que o ECA representa um avanço para que a sociedade lute pela efetivação de direitos, uma vez que supõe a ruptura com práticas discriminatórias do passado.

$\mathrm{O}$ reconhecimento dos direitos de cidadania de crianças e adolescentes corresponde à evolução dos direitos humanos no Brasil, porque introduz um novo paradigma que os consagra como pessoas em desenvolvimento biopsicossocial, sujeitos de direitos. Este novo tratamento 
difere substancialmente dos termos do antigo Código de Menores (BRASIL, 1979) ${ }^{4}$, que vigorou no Brasil até o final da década de 1980. Este baseava-se em pressupostos que discriminavam crianças e adolescentes em situação de pobreza e de exclusão, pois associava pobreza com delinquência. Isso, apesar da sua reformulação em 1979 (fora criado em 1927), após a promulgação da Declaração Internacional dos Direitos da Criança em 1959. A nova perspectiva aberta pelo ECA pressupõe, pois, a superação do enfoque que era dado pelo Código de Menores.

Além de regular as conquistas em favor de crianças e adolescentes expressos na $\mathrm{CF}$, o ECA promove um conjunto de mudanças que extrapola o campo jurídico e desdobra-se na realidade da política e sociedade do país. "Sua implantação pressupõe ações do poder público e da sociedade civil, articuladas, sintonizadas e concatenadas entre si" (RUDGE, 2007, p. 88), o que supõe a existência de um sistema, de um todo organizado, que conforma a política pública de atendimento aos direitos da criança e do adolescente dentro de uma nova forma de gestão pública. Tal política possui uma natureza intrinsecamente diferente das políticas setoriais (aquelas voltadas a cada uma das diferentes áreas: saúde, educação, assistência social, emprego, saneamento básico, alimentação, habitação, segurança, transporte, entre outras), pois se define por seu público alvo - a crianças e adolescentes -, tendo por objetivo a garantia de todos os seus direitos fundamentais.

A política de atendimento aos direitos da criança e do adolescente seria implantada por meio de um "conjunto articulado de ações governamentais e não-governamentais, da União, dos Estados, do Distrito Federal e dos municípios" (BRASIL, ECA, art. 86), o que pressupõe ações sintonizadas, concatenadas entre si, envolvendo o poder público e a sociedade civil. De acordo com Rudge (2009), nessa concepção está implícita a ideia de sistema, ou seja, de um todo organizado que perpassa os setores responsáveis pela prestação de serviços destinados à população infanto-juvenil, cuja execução pressupõe e requer uma articulação orgânica e permanente com as demais políticas sociais. No entanto, de acordo com Leite e Duarte (2005), as políticas sociais brasileiras se ressentem de uma abordagem integrada, uma vez que não atuam em conjunto e não dialogam entre si, não havendo um esforço sistemático institucionalizado para compatibilização das ações e construção de complementaridades.

${ }^{4}$ Em 12 de outubro de 1927, o presidente Washington Luiz assinou uma lei que ficou conhecida como Código de Menores e que estabeleceu que o jovem é penalmente inimputável até os 17 anos e que somente a partir dos 18 responde por seus crimes e pode ser condenado à prisão. O código de 1927 foi a primeira lei do Brasil dedicada à proteção da infância e da adolescência. Até então, a Justiça era inclemente com os pequenos infratores. Pelo Código Penal de 1890, criado após a queda do Império, crianças podiam ser levadas aos tribunais a partir dos 9 anos da mesma forma que os criminosos adultos (WESTIN, 2015). 
As linhas de ação para implementação dessa política de atendimento infanto-juvenil estão definidas no art. 87 do ECA. Ainda de acordo com Rudge (2019), são três eixos. O primeiro consiste no estabelecimento de políticas sociais básicas e consistentes que garantam as necessidades primordiais de saúde, educação, cultura, alimentação, esporte, lazer e profissionalização. Têm caráter universalizante, isto é, são destinadas a todas as crianças e adolescentes, independentemente da sua condição socioeconômica e cultural. O segundo determina o estabelecimento de políticas e programas de assistência social para aquelas crianças e adolescentes que deles necessitarem. Isso porque uma política de assistência social não é destinada ao universo da população, mas aos grupos sociais que se encontram em estado de necessidade ou vulnerabilidade. Já o terceiro propõe a organização de uma rede de serviços especiais de prevenção e atendimento às vítimas de negligência, maus tratos, exploração, abuso, crueldade e opressão. Referem-se a programas de proteção especial, destinados às crianças e adolescentes em situação de risco pessoal e envolvem uma ação articulada da Assistência Social com a Justiça da Infância e Juventude, o Ministério Público e a Segurança Pública. O Quadro 1 apresenta uma síntese dos três eixos.

Quadro 1 - As linhas de ação do Estatuto da Criança e do Adolescente

\begin{tabular}{|c|c|c|}
\hline $\mathbf{1}^{\mathbf{0}}$ eixo & $\mathbf{2}^{\mathbf{0}}$ eixo & $\mathbf{3}^{\mathbf{0}}$ eixo \\
\hline $\begin{array}{c}\text { Políticas Sociais } \\
\text { Básicas }\end{array}$ & $\begin{array}{c}\text { Políticas e programas de } \\
\text { Assistência Social }\end{array}$ & $\begin{array}{c}\text { Programas de } \\
\text { Proteção Especial }\end{array}$ \\
\hline $\begin{array}{c}\text { Voltadas à garantia dos } \\
\text { direitos e necessidades de } \\
\text { todos: saúde, educação, } \\
\text { cultura, trabalho. }\end{array}$ & $\begin{array}{c}\text { Destinadas às crianças e } \\
\text { adolescentes que se encontram em } \\
\text { estado de vulnerabilidade social. }\end{array}$ & $\begin{array}{c}\text { Fixados para crianças e } \\
\text { adolescentes em } \\
\text { situação de risco } \\
\text { pessoal. }\end{array}$ \\
\hline
\end{tabular}

Fonte: Rudge (2007, p. 89)

Ao adotar os princípios da descentralização político-administrativa e da participação da sociedade civil na formulação das políticas e no controle das ações, consagrados no art. 204 da $\mathrm{CF}$, o ECA se fundamenta nas seguintes ideias:

1- É no município que as demandas, conflitos e necessidades estão postas e é nesse espaço que as estratégias para superá-las devem acontecer; assim, a municipalização do atendimento, em consonância com o princípio constitucional de descentralização político-administrativa, é diretriz prioritária no processo do estabelecimento de ações fundamentais de atenção à criança e ao adolescente previsto pelo ECA.

2 - Do ponto de vista organizacional, mudanças quanto à forma de gerir a política de atendimento à infância e à adolescência implicam revisão de competências e papéis desempenhados pelas instâncias do poder executivo federal, estadual e municipal, bem como um redimensionamento da relação 
entre Estado e sociedade; a CF também contempla como princípio a participação da população por meio de entidades representativas da sociedade civil. A forma encontrada para a efetivação desta participação foi a constituição de conselhos representativos visando uma maior transparência nas ações do poder público e à garantia de um processo democrático de cogestão ${ }^{5}$ (RUDGE, 2009, p. 89).

Condizente a essa política, o ECA propõe a criação do conselho nacional e de conselhos estaduais e municipais dos direitos da criança e do adolescente, órgãos deliberativos e controladores das ações em cada um dos níveis, aos quais é assegurada a participação popular paritária, sendo constituídos metade por representantes do poder público e metade por representantes da sociedade civil. Seus recursos destinam-se ao estabelecimento das políticas, programas e ações voltadas ao atendimento dos direitos das crianças e adolescentes, conforme deliberações dos conselhos aos quais se vinculam. Uma outra particularidade do ECA é apresentar uma interface entre o poder executivo e o poder judiciário, o que confere o respaldo necessário nas situações que envolvem conflitos.

Antes de chegar aos conselhos municipais cabe esclarecer os antecedentes que levaram à propositura de criação destes, falando do Conselho Nacional dos Direitos da Criança e do Adolescente (Conanda).

\section{O Conselho Nacional dos Direitos da Criança e do Adolescente (Conanda)}

Segundo Gomes da Costa (2016), a criação do Conanda est vinculada a dois processos sociais. O primeiro diz respeito ao contexto de redemocratização e de incentivo ampliação da participação da sociedade nas decisões governamentais sobre políticas sociais, bem como no controle da implantação destas. O segundo, reflete uma nova visão sobre os direitos de crianças e adolescentes que visa concretizar princípios, como o da prioridade absoluta e o da proteção integral, a partir da implantação do chamado sistema de garantias de direitos, baseado na CF e no ECA.

O Conanda, órgão colegiado de caráter deliberativo, nasceu, conforme previsto no art. 88 do ECA, como o principal órgão do sistema de garantia de direitos. Foi criado em 1991 pela Lei n. 8.242 (BRASIL, 1991) e regulamentado pelo Decreto n. 5.089/2004 e pela Resolução n. 105/2005. Tem, conforme consta no Portal dos Direitos da Criança e do Adolescente (BRASIL, s/d), dentre outras atribuições:

${ }^{5}$ Cogestão é entendida como um processo que consiste na partilha de responsabilidades entre as instâncias de governo e a sociedade civil organizada na tomada de decisões e na implementação conjunta de medidas no intento de otimizar a utilização dos recursos. 
- definir as diretrizes para a Política Nacional de Promoção, Proteção e Defesa dos Direitos de Crianças e Adolescentes;

- fiscalizar as ações executadas pelo poder público no que diz respeito ao atendimento da população infanto-juvenil;

- fazer a gestão do Fundo Nacional da Criança e do Adolescente (FNCA);

- Definir as diretrizes para a criação e o funcionamento dos Conselhos Estaduais, Distrital e Municipais dos Direitos da Criança e do Adolescente e dos Conselhos Tutelares.

Inicialmente o Conanda fazia parte da estrutura básica da Secretaria de Direitos Humanos da Presidência da República (SDH/PR). Atualmente, integra a estrutura organizacional do Ministério da Mulher, da Família e dos Direitos Humanos (MMFDH). Em 1991, quando foi criado, a formação prevista era paritária, com 28 membros: 14 representantes eleitos da sociedade civil e 14 representantes do Governo Federal, sendo que 14 ministérios indicavam um membro cada, mediante a compreensão de que os direitos da criança e do adolescente deveriam ser objeto de políticas transversais.

Porém, em 2019, houve uma reviravolta. O Conanda sofreu alterações por meio do Decreto Presidencial n. 10.003, de 4 de setembro, o qual definiu que os membros do conselho passariam a ser escolhidos por processo seletivo e não por eleição. Também foi reduzida a participação da sociedade civil para nove conselheiros, deixando o governo federal com maioria de 13 membros, com representantes de três ministérios. O presidente do colegiado, que era eleito pelos membros, passa a ser escolhido pelo presidente da República. Os conselheiros que tomaram posse em março de 2019, e atuariam até 2021, tiveram seus mandatos suspensos. À época da elaboração deste texto (fev. 2020), a medida presidencial estava sendo objeto de arguição por descumprimento de preceito constitucional, com pedido de medida cautelar por parte do Ministério Público, sendo que o decreto presidencial foi suspenso por um ministro do Supremo Tribunal Federal em 19 de dezembro de 2019, surgindo um vácuo legal até que a questão fosse definitivamente resolvida.

O Fundo Nacional da Criança e do Adolescente (FNCA), cuja criação foi disposta no art. $6^{\circ}$ da mesma lei n. 8.242/1991, tem seus recursos provenientes principalmente de doações de pessoas físicas e jurídicas, dedutíveis do imposto de renda, recursos consignados no orçamento da União e contribuições de governos e organismos internacionais.

\section{O Conselho Municipal dos Direitos da Criança e do Adolescente}


O Conselho Municipal dos Direitos da Criança e do Adolescente é o órgão responsável pela formulação e deliberação da política de atendimento e pelo controle das ações voltadas a crianças e adolescentes na esfera do município. Tem como missão a elaboração do Plano Municipal da Criança e do Adolescente que dá corpo e visibilidade à Política de Atenção Integral à Criança e ao Adolescente do Município. Nessa formulação dois pontos devem ser contemplados: a análise da situação da criança e do adolescente e, em função dela, a priorização de programas, ações e projetos.

Entende-se que o conhecimento da realidade local e da situação das crianças e adolescentes é fundamental no processo de formulação da política de atendimento, pois permite estabelecer a priorização das ações e a definição de quais áreas receberão maior concentração de recursos financeiros e quais programas serão desenvolvidos. Outra questão relevante diz respeito a como definir as competências das diferentes secretarias municipais e das entidades não-governamentais no atendimento a ser prestado, considerando a ideia de que estratégias participativas contribuem para o envolvimento da população de forma mais ativa, como afirma Rudge (2009, p. 90):

Vários são os caminhos possíveis para se chegar ao conhecimento da realidade municipal sobre a situação da infância e da adolescência e ao estabelecimento de prioridades, mas, com certeza, com a participação dos vários atores locais na apreensão e no conhecimento da realidade esse processo se torna muito mais vivo, dinâmico e legítimo. A experiência aponta que estratégias participativas têm se mostrado muito mais eficientes, gerando resultados mais significativos, uma vez que os dados são absorvidos e amadurecidos pelo grupo que atuará no processo de mudança do desempenho das políticas públicas locais.

Ao Conselho Municipal dos Direitos da Criança e do Adolescente compete zelar pelo cumprimento dos dispositivos constantes no ECA (Capítulo IV - do Direito à Educação, à Cultura, ao Esporte e ao Lazer) e na LDB (Título III - Do direito à Educação e do Dever de Educar). Suas ações devem ser articuladas às do Conselho Municipal de Educação ${ }^{6}$, de forma a garantir o acesso de todas as crianças ao ensino e a um tratamento digno na escola, respeitando as diferenças de classe, gênero, raça e de desempenho. Portanto, são requisitos que os

${ }^{6}$ O Conselho Municipal de Educação (CME) é instituído por meio de lei municipal. Os conselheiros são definidos por eleição ou indicação, conforme a lei aprovada. Compete ao município garantir a infraestrutura que possibilite as reuniões periódicas, materiais e equipamentos. Funciona como mediador da relação entre a sociedade e os gestores da Educação municipal. Principais funções: elaborar, em conjunto coma Secretaria Municipal de Educação; normatizar determinações estaduais e federais, adaptando-as ao município; deliberar sobre o funcionamento de escolas públicas municipais e da rede privada de ensino e sobre o currículo das escolas municipais; legalizar cursos; assessorar na resposta a questionamentos e dúvidas do poder público e da sociedade, emitindo pareceres; fiscalizar e acompanhar a execução das políticas públicas e monitorar os resultados educacionais do sistema municipal. 
conselheiros conheçam a legislação, tracem estratégias para acompanhar e analisar o desempenho da política municipal de educação, tenham acesso aos dados e indicadores educacionais da cidade e saibam interpretá-los.

Essa concepção participativa de gerir a coisa pública é bastante desafiadora. De um lado, as instituições públicas nem sempre estabelecem práticas participativas em suas gestões; de outro, não há uma tradição participativa na sociedade civil. Por isso, a abertura de espaços de discussão das políticas públicas e de ações concretas destinadas ao atendimento de crianças e adolescentes significa investir na construção e na solidificação de uma sociedade mais justa e democrática, ou seja, é uma questão pedagógica e educativa.

\section{O Conselho Tutelar}

O ECA prevê ainda a criação de outro órgão que compõe a política de atendimento e que pressupõe também a participação da sociedade no equacionamento das questões ligadas à infância e juventude no município: o Conselho Tutelar que, como define o art. 131, "é órgão permanente e autônomo, não jurisdicional, encarregado pela sociedade de zelar pelo cumprimento dos direitos da criança e do adolescente".

O Conselho Tutelar é fundamental para a política de atendimento em um município, pois trabalha com o paradigma de afirmação de direitos e não mais com a lógica correcional e repressiva que caracterizava anteriormente o atendimento a crianças e adolescentes e suas famílias expostas a situação de pobreza e de vulnerabilidade social. A existência do Conselho Tutelar quebra com a lógica da criminalização e da desestruturação familiar e volta o foco da ação pública para a garantia de direitos sociais.

A diferença é que, enquanto os Conselhos de Direitos operam nas questões referentes à formulação de políticas voltadas à garantia dos direitos fundamentais, os Conselhos Tutelares atuam nos casos particulares de descumprimento ou violação dos direitos das crianças e dos adolescentes.

Cabe ao executivo municipal garantir recursos para financiar a infraestrutura para o funcionamento desse serviço público. A criação do Conselho Tutelar se dá por meio de lei municipal que define a modalidade de eleição dos conselheiros, bem como sua remuneração. A eleição que pode ser: direta - universal e facultativa, por meio do voto direto da população em todos os candidatos que se apresentarem, ou indireta - por meio de um colégio eleitoral formado por representantes da sociedade civil, em que apenas os representantes votam nos candidatos. Em qualquer das modalidades, há que se garantir legitimidade e transparência ao processo, 
sendo a eleição realizada sob responsabilidade do Conselho Municipal dos Direitos e sob fiscalização do Ministério Público.

Mesmo não sendo um órgão executivo, o Conselho Tutelar é um espaço de denúncia e de defesa em casos de negligência, opressão, abandono, exploração e discriminação praticados contra a criança e o adolescente. Sua atribuição é receber queixas, denúncias e reclamações sobre situações de crianças e adolescentes cujos direitos foram ameaçados ou violados, inclusive sobre a não oferta ou a oferta irregular de serviços e programas públicos de atendimento, e tomar providências para que a situação seja resolvida, inclusive com notificações ao Poder Judiciário quando necessário. Entende-se que um direito esteja ameaçado quando um indivíduo corre o risco de ser privado de bens materiais e imateriais. A violação do direito existe quando essa privação se concretiza. No caso dos direitos infanto-juvenis, podemos exemplificar a violação do direito à integridade física e psíquica quando crianças e adolescentes são abusados ou explorados sexualmente, quando são vítimas de castigos físicos, quando são exploradas como mão de obra para trabalhos incompatíveis à sua compleição física, psíquica e à sua condição de aprendiz. Seguem as atribuições detalhadas do Conselho Tutelar, conforme o artigo 136 do ECA (Quadro 2).

Quadro 2 - Atribuições do Conselho Tutelar, conforme o artigo 136 do ECA

- Atender as crianças e adolescentes cujos direitos constitucionais estejam ameaçados ou foram violados, aplicando a eles as medidas de proteção previstas pelo ECA;

- Atender e aconselhar os pais ou responsáveis, nos casos de ameaça ou violação de direitos e aplicar a eles medidas necessárias;

- Requisitar serviços públicos nas áreas de saúde, educação, serviço social, previdência, trabalho e segurança e acionar a justiça quando as suas deliberações não forem cumpridas;

- Encaminhar ao Ministério Público notícia de fato que constitua infração administrativa (por exemplo, quando o médico, professor ou responsável por estabelecimento de atenção à saúde e de ensino fundamental, pré-escola ou creche, deixarem de comunicar à autoridade competente os casos de que tenha conhecimento, envolvendo suspeita ou confirmação de maus-tratos) ou penal (por exemplo, submeter a criança ou adolescente a abuso, tortura ou maus tratos) contra os direitos da criança ou adolescente;

- Tomar providências para que as medidas de proteção sejam efetivamente cumpridas;

- Expedir notificações nos casos de sua competência;

- Comunicar ao Juiz da Infância e da Juventude para que esse requisite certidões de nascimento e de óbito de criança ou adolescente quando necessário;

- Assessorar o Poder Executivo local na elaboração da proposta orçamentária para planos e programas de atendimento dos direitos da criança e do adolescente;

- Levar ao Ministério Público conhecimento dos casos que demandem ações judiciais de perda ou suspensão do poder familiar; 
- Fiscalizar, conjuntamente com o Ministério Público e o Poder Judiciário, as entidades governamentais e não governamentais que executam programas de proteção e socioeducativos para crianças e adolescentes.

Fonte: ECA (1990, art. 136)

É bom enfatizar que os direitos fundamentais de crianças e adolescentes podem ser ameaçados por ação ou por omissão do poder público, que viola direitos quando deixa de oferecer ou oferece de forma irregular serviços e programas de atendimento básico e de assistência social. Os pais ou responsáveis também podem ser os violadores quando deixam de assistir, cuidar, proteger e educar seus filhos. É dever dos pais garantir que as necessidades básicas dos filhos sejam atendidas, e sua ausência coloca as crianças e adolescentes em situação de vulnerabilidade.

Em qualquer desses casos o Conselho Tutelar deve ser acionado por entidades da sociedade civil, por técnicos do poder público ou pelos cidadãos, para que tome as providências cabíveis, aplicando as medidas de proteção previstas pelo ECA. Tanto o Juiz da Infância e da Juventude quanto o Conselho Tutelar podem aplicar essas medidas e exigir que elas sejam cumpridas (pelas famílias, por órgãos do poder público ou entidades da sociedade civil), não cabendo a eles a sua execução.

O Poder Judiciário, o Ministério Público e o Conselho Tutelar são instâncias que compõem o Sistema de Garantia de Direitos, que têm como objetivo assegurar as condições de exigibilidade dos direitos da criança e do adolescente contidos na Constituição e no ECA. Apesar das especificidades das suas atribuições, é fundamental que trabalhem organicamente, estabelecendo uma relação de complementaridade.

As medidas de proteção, pelos conselheiros, podem ser, por exemplo, convocar os pais ou responsáveis para que tomem ciência dos direitos que estão sendo violados e para que zelem pelo cumprimento de seus deveres, ou encaminhar crianças e adolescentes para atendimento em serviços de orientação, apoio e acompanhamento temporários.

A medida de proteção diretamente vinculada à educação escolar refere-se à garantia de matrícula e de frequência em estabelecimento oficial de ensino. É dever dos pais e responsáveis matricular e controlar a frequência dos filhos na escola. Caso deixem de cumprir esse dever, o Conselho Tutelar deve orientar a família e acompanhar o caso até sua regularização.

Por sua vez, os dirigentes escolares têm o dever de efetivar a matrícula, de acompanhar a frequência dos alunos e de comunicar ao Conselho Tutelar, uma vez esgotados os recursos escolares, casos de reiteração de faltas injustificadas e de evasão escolar (art. 56 do ECA); cabe- 
lhes ainda, sob pena de responsabilização penal, denunciar casos em que há suspeita maustratos, violência, abusos e negligência contra crianças e adolescentes.

Como se vê, o papel da escola é fundamental na prevenção e na denúncia de casos de violência física, sexual e psicológica contra crianças e adolescentes. A notificação de casos de violência é obrigatória e a responsabilidade do profissional da educação é intransferível, podendo ser cobrada judicialmente, conforme o artigo 13 do ECA: "os casos de suspeita ou confirmação de maus-tratos contra criança ou adolescente serão obrigatoriamente comunicadas ao Conselho Tutelar da respectiva localidade, sem prejuízo de outras providencias legais". Não se trata, portanto, de apenas uma questão de consciência. Inclusive, no art. 245, o ECA estabelece multa para o responsável que deixe de comunicar à autoridade competente os casos envolvendo suspeita ou confirmação de maus-tratos dos quais tenha conhecimento. O Conselho Tutelar é considerado nestes casos como uma autoridade competente para dar os encaminhamentos necessários de acordo com suas atribuições, entre elas a de invocar o Poder Judiciário para a resolução de conflitos que não sejam solucionados na sua esfera de ação.

A esse respeito, Deslandes (1994) define abuso ou maus-tratos pela existência de um sujeito em condições superiores (idade, força, posição social ou econômica, inteligência, autoridade) que comete um dano físico, psicológico ou sexual, contrariamente à vontade da vítima ou por consentimento obtido a partir de indução ou sedução enganosa. Apresento no Quadro 3 as formas mais comuns de maus-tratos e violências às quais as crianças e adolescentes são submetidos.

Quadro 3 - Formas de maus-tratos e violências contra crianças e adolescentes

\begin{tabular}{|c|c|}
\hline Violência física & $\begin{array}{l}\text { Agressões com o uso da força física, de forma intencional e não acidental, } \\
\text { deixando ou não marcas evidentes. }\end{array}$ \\
\hline $\begin{array}{l}\text { Violência } \\
\text { sexual }\end{array}$ & $\begin{array}{l}\text { É qualquer atividade com uma criança, antes da idade de consentimento } \\
\text { legal, que vise à gratificação sexual de um adulto ou de uma criança muito } \\
\text { maior. Caracteriza-se por: } \\
\text { - } \quad \text { Práticas sexuais que não envolvem contato físico - assédio sexual, abuso } \\
\text { sexual verbal, exibicionismo, voyeurismo; } \\
\text { - Abuso sexual com contato físico - atentado violento ao pudor, estupro, } \\
\text { sedução; } \\
\text { - Exploração sexual comercial - caracterizada pela relação sexual de } \\
\text { crianças e adolescentes com adultos, mediada por dinheiro ou pela troca } \\
\text { de favores. }\end{array}$ \\
\hline $\begin{array}{l}\text { Violência } \\
\text { psicológica }\end{array}$ & $\begin{array}{l}\text { São todas as formas de rejeição, depreciação, discriminação, desrespeito, } \\
\text { cobrança ou punição exageradas e utilização da criança ou adolescente. } \\
\text { Podem causar danos ao desenvolvimento da criança. }\end{array}$ \\
\hline
\end{tabular}




\begin{tabular}{|l|l|}
\hline Negligência & $\begin{array}{l}\text { É o ato de omissão do responsável pela criança ou adolescente em prover as } \\
\text { necessidades básicas para o seu desenvolvimento (ABRAPIA, 1997) }\end{array}$ \\
\hline
\end{tabular}

Fonte: Rudge (2009, p. 93)

Quando o Conselho Tutelar recebe uma comunicação de maus tratos deve solicitar o estudo do caso junto aos órgãos de assistência do município para verificação da situação familiar onde a criança ou adolescente vive. No caso de faltas injustificadas deve comunicar a família, alertando-a para o direito à educação de seus filhos e as implicações do excesso de faltas no desempenho escolar. Em relação à observação de elevados índices repetência em determinada unidade escolar, o Conselho Tutelar deve buscar esclarecimentos sobre o fato junto ao dirigente escolar, alertá-lo para a necessidade de planejamento de intervenção pedagógica e levar a situação ao conhecimento do Conselho dos Direitos da Criança e do Adolescente da cidade, caso haja reiteração. No caso do não atendimento às orientações, o Conselho Tutelar deverá apresentar o caso à Justiça da Infância e da Juventude.

O Conselho Tutelar pode solicitar aos órgãos municipais competentes a inclusão das famílias em programas de auxílio e requisitar tratamento médico, psicológico ou psiquiátrico e de atendimento a dependentes de álcool e de drogas. Na ausência desses serviços, no âmbito do município, cabe-lhe notificar as autoridades responsáveis pela política municipal de saúde para as providências e encaminhamentos alternativos.

Enfim, a criação dos Conselhos Tutelares representou um avanço no estabelecimento de direitos, uma vez que assumiram algumas atribuições anteriormente exercidas pela Justiça da Infância e da Juventude. Frente à amplitude de suas atribuições, entende-se que os Conselhos Tutelares devem estar em estreita relação com o executivo municipal na formulação das políticas públicas das diversas áreas voltadas à garantia dos direitos das crianças e adolescentes e na seleção de prioridades municipais da política de atendimento previstos no ECA, inclusa a área da educação.

A despeito dessa importância, ainda encontramos no cenário nacional conselhos tutelares frágeis, com muitas indagações e dúvidas quanto ao seu papel e sem infraestrutura suficiente para o desempenho do trabalho a ser desenvolvido. Os conselheiros precisam ser formados e estar em constante processo de aprimoramento da sua prática. Os Conselhos devem se constituir em espaços formativos e de reflexão, valorizando a própria experiência e 
estabelecendo trocas entre seus componentes de ideias e experiências com outros Conselhos existentes na cidade e com Conselhos Tutelares de outras localidades ${ }^{7}$.

\section{A justiça da infância e da juventude ${ }^{8}$}

É de competência exclusiva da autoridade judiciária conhecer representações apresentadas pelo Ministério Público para apuração de ato infracional atribuído a adolescente, aplicando as medidas cabíveis. Também é de sua competência acolher e decidir sobre pedidos de adoção, guarda e tutela, bem como sobre ações decorrentes de irregularidades em entidades de atendimento, aplicando as medidas cabíveis.

A Justiça da Infância e da Juventude tem suas competências elencadas no art. 148 do ECA. Frente a um caso, a competência de jurisdição é determinada pelo domicílio dos pais ou responsáveis, ou, na falta destes, pelo lugar onde se encontrar a criança ou o adolescente, em um abrigo, por exemplo. Quando um problema se refere a um ato infracional, a autoridade competente é a do lugar onde ocorreu a ação.

A autoridade judiciária também possui outras competências para disciplinar por meio de portarias, e de autorizar, por meio de alvarás, a entrada e a permanência da criança ou adolescente, desacompanhado dos pais ou responsáveis, em estádios, bailes, boates etc. Tudo isso se encontra discriminado no art. 149 do ECA. Dentre outras, é de competência exclusiva da autoridade judiciária conhecer representações promovidas pelo Ministério Público para apuração de ato infracional atribuído a adolescente, aplicando as medidas cabíveis. Também compõem a Justiça da Infância e da Juventude equipes interprofissionais, mantidas com recursos do Poder Judiciário, conforme previsto no art. 151 do ECA.

\section{Considerações finais}

Face ao exposto, conclui-se que não falta no Brasil legislação sobre o amparo e a garantia do direito à educação aos cidadãos que se encontram na faixa etária de até os 18 anos.

\footnotetext{
${ }^{7}$ Existem vários cursos de formação de conselheiros tutelares. A Escola Virtual.Gov - EV.G, por exemplo, tem um portal para a oferta de capacitação a distância (https://www.escolavirtual.gov.br). Estados e municípios também oferecem cursos, como por exemplo, a Escola do Parlamento, da Câmara Municipal de São Paulo, com o curso de Formação de Conselheiros Tutelares, exclusivo para a cidade de São Paulo. Disponível em: http://www.saopaulo.sp.leg.br/escoladoparlamento/cursos/cursos-anteriores/cursos-realizados-2018/formacaode-conselheiros-tutelares/. Acesso em: 10 set. 2020.

${ }^{8}$ No Brasil, a jurisdição é exercida com exclusividade pelo Poder Judiciário. Por critérios de conveniência, a jurisdição é dividida por matérias e locais, no que se convencionou chamar competência. É por isso que em cada comarca existem Varas da Família, da Fazenda Pública, Criminal e da Infância e da Juventude (PORTALEDUCAÇÃO, s/d).
} 
Os Conselho dos Direitos e os Conselhos Tutelares são instâncias públicas criadas pelo ECA que atuam diretamente nas cidades e devem ser valorizados, apoiados e implementados como uma estratégia para quebrar o ciclo de exclusão social e de violação de direitos vivenciados por crianças e adolescentes brasileiros (RUDGE, 2009).

Observa-se, ao mesmo tempo que, na prática, há dificuldade de efetivar medidas protetivas, principalmente para crianças em situação de extrema pobreza, além de identificarse a sobreposição de funções e a ausência de diálogo entre as várias instâncias do poder público na resolução dos problemas. Lembrando que, por trás de trás de cada criança e adolescente desamparado, há uma família igualmente desamparada da perspectiva econômica e social.

\section{REFERÊNCIAS}

ABRAPIA. Associação Brasileira Multiprofissional de Proteção à Infância e à Adolescência. Maus-tratos contra crianças e adolescentes. Proteção e prevenção: guia de orientação para educadores. Petrópolis: Autores \& Agentes \& Associados, Abrapia, 1997.

BANDEIRA, V. N. Adolescente em liberdade assistida: análise quanto às dificuldades de (re)inserção na rede regular de ensino público em um município do interior paulista. 2016. Dissertação (Processos de Ensino, Gestão e Inovação) - Universidade de Araraquara (UNIARA), Araraquara, 2016.

BRASIL. Lei n. 6.697, de 10 de outubro de 1979. Institui o Código de Menores. Diário Oficial da União: Seção 1, Brasília, DF, p. 14945, 11 out. 1979. PL 1573/1975

BRASIL. Constituição (1988). Constituição da República Federativa do Brasil. Brasília, DF: Senado, 1988.

BRASIL. Lei n. 8.069 de 13 julho 1990. Dispõe sobre o Estatuto da Criança e do Adolescente. Diário Oficial da União: Seção 1, Brasília, DF, p. 13563, 16 jul. 1990. PL $5172 / 1990$

BRASIL. Lei n. 8.242, de 12 de outubro de 1991. Cria o Conselho Nacional dos Direitos da Criança e do Adolescente (Conanda) e dá outras providências. Diário Oficial da União: Seção 1, Brasília, DF, p. 22589, 16 out. 1991. PL 514/1991

BRASIL. Lei n. 8.742, de 7 de dezembro de 1993. Lei Orgânica da Assistência Social LOAS. Diário Oficial da União: Seção 1, Brasília, DF, p. 18769, 8 dez. 1993. PL 4100/1993

BRASIL. Lei n. 9.394, de 20 de dezembro de 1996. Lei de Diretrizes e Bases da Educação Nacional. Diário Oficial da União: Seção 1, Brasília, DF, n. 248, p. 27833, 23 dez. 1996. PL $1258 / 1988$

BRASIL. Decreto n. 9.579, de 22 de novembro de 2018. Consolida atos normativos editados pelo Poder Executivo federal que dispõem sobre a temática do lactente, da criança e do adolescente e do aprendiz, e sobre o Conselho Nacional dos Direitos da Criança e do 
Adolescente, o Fundo Nacional para a Criança e o Adolescente e os programas federais da criança e do adolescente, e d outras providências. Diário Oficial da União: Seção 1, Brasília, DF, p. 2, 5 set. 2019.

BRASIL. Decreto n. 10.003, de 4 de setembro de 2019. Altera o Decreto $\mathrm{n}^{\circ}$ 9.579, de 22 de novembro de 2018, para dispor sobre o Conselho Nacional dos Direitos da Criança e do Adolescente. Diário Oficial da União: Seção 1, Brasília, DF, p. 49, 23 nov. 2018.

BRASIL. Portal dos Direitos da Criança e do Adolescente. Disponível em: https://www.direitosdacrianca.gov.br/conanda. s/d. Acesso em 26 fev. 2020.

CRUXÊN, I. (Red.); ALENCAR J. L. O.; FONSECA, I. F. (Coord.). O Conselho Nacional dos Direitos da Criança e do Adolescente na visão de seus conselheiros. Relatório de Pesquisa Projeto Conselhos Nacionais: perfil e atuação dos conselheiros. Brasil Governo Federal/Secretaria de Assuntos Estratégicos da Presidência da República. Instituto de Pesquisa Econômica Aplicada/Ipea, 2012.

DESLANDES, S. F. Atenção a crianças e adolescentes vítimas de violência doméstica. Caderno Saúde Pública, Rio de Janeiro, n. 10, 1994.

ESTEVES, R. F. Gestão pedagógica na educação infantil: a relação da escola com as famílias de alunos ingressantes. 2019. 94 f. Dissertação (Mestrado em Processos de Ensino, Gestão e Inovação) - Universidade de Araraquara (UNIARA), Araraquara, 2019.

GOMES DA COSTA, A. C. O ECA e a Lei Orgânica da Assistência Social (LOAS). 30 nov. 2016. Fundação Telefônica. Disponível em:

http://fundacaotelefonica.org.br/promenino/trabalhoinfantil/noticia/o-eca-e-a-lei-organica-daassistencia-social-loas/. Acesso em: 27 fev. 2019.

LEITE, M. R. S. D. T; DUARTE, V. C. Desafio da articulação entre políticas setoriais e intersetoriais: o caso da educação. In: CONGRESO INTERNACIONAL DEL CLADE SOBRE LA REFORMA DEL ESTADO Y DE LA ADMINISTRACIÓN PÚBLICA, 5. 2005, Santiago. Anais [...]. Santiago, Chile, 2005.

ONU. Organização das Nações Unidas. Declaração dos Direitos da Criança. Proclamada pela Resolução n. 1386, da Assembleia Geral das Nações Unidas, em 20 de novembro de 1959. Disponível em: http://www.direitoshumanos.usp.br/index.php/Criança/declaracao-dosdireitos-da-crianca.html. Acesso em: 27 fev. 2020.

RUDGE, M. A. L. A atuação dos conselhos na perspectiva do direito à educação. In: FALSARELLA, A. M.; FONSECA, V. N. (Coord.). Coleção Diálogos sobre a Gestão Municipal. O cotidiano do gestor: temas e práticas. São Paulo: Centro de Estudos e Pesquisas em Educação, Cultura e Ação Comunitária (Cenpec)/Fundação Itaú Social, 2009. Cad. 3. p. $87-98$.

WESTIN, R. Crianças iam para a cadeia no Brasil até a década de 1920. Agência Senado/senadonotícias. Disponível em:

https://www12.senado.leg.br/noticias/materias/2015/07/07/criancas-iam-para-a-cadeia-nobrasil-ate-a-decada-de-1920. Acesso em: 27 fev. 2020. 


\section{Como referenciar este artigo}

FALSARELlA, A. M. Os Conselhos de Defesa de Direitos das Crianças e Adolescentes e o Direito à Educação. Revista on line de Política e Gestão Educacional, Araraquara, v. 25, n. 1, p. 68-85, jan./abr. 2021. e-ISSN:1519-9029. DOI: https://doi.org/10.22633/rpge.v25i1.13414

Submetido em: 03/03/2020

Revisões requeridas em: 30/06/2020

Aceito em: 09/11/2020

Publicado em: 02/01/2021 